IN BRIEF

\section{JET meeting}

The Committee of Permanent Representatives (COREPER) in Brussels, made up of senior officials of the EEC member states, meets this week to discuss the ill-starred joint fusion project, JET. If they can resolve the outstanding problem of the method by which the proposed JET council will work, the way will be clear for an early Council of Ministers meeting to finalise the question of the site, which is expected to be either Garching in Germany or Culham in England.

\section{Argentinian disappears}

The latest Argentinian scientist about whom concern is being expressed is Horacio Dottori, an astrophysicist. Sr Dottori was at the Cordoba Astronomical Observatory from 1967 to 1976 except for a two-year period in Germany at the Max Planck Institut für Physik und Astrophysik from 1971-73.
He worked on observations of peculiar and interacting galaxies. In March 1976, following the military takeover, he was dismissed. He was arrested in August 1976 and has now disappeared; his friends believe he has been sent to a camp called 'La Perla', about which little is known.

\section{X-ray survey}

To meet the requirements of a directive on radiological protection from the EEC Council of Ministers, and because existing information in Britain is out of date, the UK National Radiological Protection Board (NRPB) is to conduct a survey, beginning in June and encompassing over 100 National Health Service hospitals, of the radiation doses which patients receive from the diagnostic use of X-rays.

The medical use of radiation contributes some $13 \%$ of the total dose which the population receives, making it the largest man-made component. Natural background radiation con- tributes some $84 \%$. The specific objective of the survey is an estimation of the so-called 'genetically significant dose' (GSD) to the population arising from diagnostic radiology.

\section{Chemistry PhD survey}

The Chemical Society's Standing Advisory Committee on Relationships between Higher Education and Industry (SACRHEI) recently completed a survey on US views of the British chemistry PhD. It sought the opinions of 40 US industrialists, seven US professors of chemistry and a couple of professional associations. Although about half the industrialists and academics thought the British and American PhDs comparable so far as research is concerned, the industrialists thought holders of British chemistry PhDs were less motivated towards employment in industry and had less appreciation of overall industrial problems than their American counterparts.
THE ban on saccharin proposed by the Food and Drug Administration (FDA) has unleashed a public reaction of unexpected, and allegedly unprecedented, intensity. The protest against the ban was apparently expected to last for only a few days and, accordingly, the US manufacturer of saccharin announced plans to discontinue production. After a week, these plans were cancelled because of the heavy and continuing demand for saccharin by consumers who were stockpiling it in various forms. This must have been a great surprise to those who thought that mere mention of carcinogenesis would make the public abjure saccharin.

I have received copies of about 150 US newspaper articles on the ban. The FDA came in for a tremendous clobbering, even though its action was mandatory under provisions of the Delaney Clause of the Federal Food Drug and Cosmetic Act. In former days, those who objected to the Clause were often rebutted by ad hominem accusations, as for example by Epstein (Preventive Medicine 2, 140, 1973):

All such criticisms fof the Delaney Clause] have emerged from industrial groups, trade associations and their consultants, and from groups that are clearly identified with protection of industrial interest . . . Such 'captive' spokesmen [are characterised by] lack of expertise and national recognition in the field of chemical carcinogenesis... No such criticisms have emerged ... from qualified scientific representatives of citizen, consumer and public interest groups.

In the face of such invective, a symposium on the Delaney Clause, held by the New York Academy of Sciences in 1973, did not produce a single proposal for its revision. Banning saccharin seems to have changed the picture. As a columnist said, "It wasn't large corporation people who

\section{Consumer revolt}

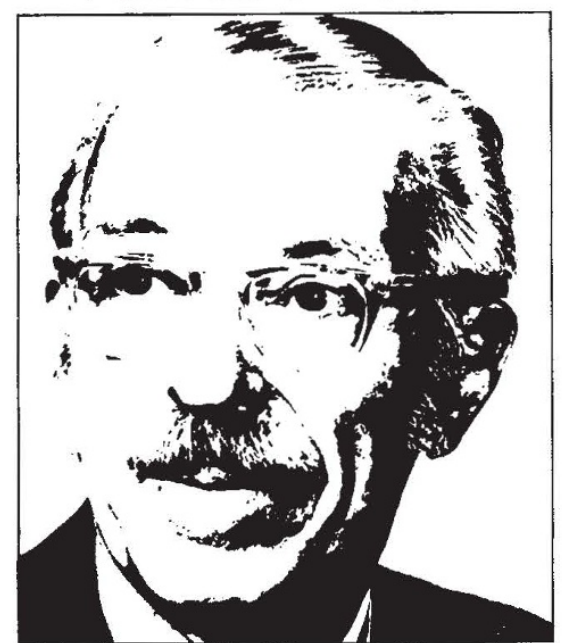

\section{THOMAS H. JUKES}

swept through supermarkets, cleaning the shelves of artificially sweetened products".

The FDA, perhaps intentionally, noted that "a human would have to drink 800 12-ounce cans of diet soda a day for a lifetime" to ingest an amount of saccharin comparable to that received by rats in the Canadian study that led to the ban. In vain did
FDA point out that one can daily would still impose a proportionately lesser risk. Cartoonists, columnists, and lawmakers swooped down gleefully on the 800-can statistic. One cartoon showed a pharmacist offering a frustrated saccharin customer cigarettes and whisky as an alternative for the banned sweetener. A congressman sought fleeting fame by introducing a bill to prohibit giving saccharin to rats. "Science For The People" had taken over, but not in the way that its sponsors had originally planned. A few stern hard-liners told diabetics to stop griping, and drink water, a sort of MarieAntoinette-in-reverse suggestion that was not well received.

Public rebuff of the Delaney Clause received support from eminent clinicians who said they had seen practically no cases of bladder cancer in diabetics who had been on saccharin for many years, thus implying that rats responded differently from human beings. Thus the two cardinal points of the Delaney Clause: extrapolation of carcinogenesis from laboratory animals to human beings, and the absence of a threshold, both were widely discounted. The Delaney Clause may well need revisions. However, let us hope that opposition to banning saccharin will not jeopardise a programme to reduce exposure to environmental carcinogens.

As of last reports, the FDA was still answering telephone calls, but Congressman James Delaney could not be reached. 